\title{
Product Design: Challenges and Evaluation
}

\author{
Pratima Bhalerao, Nilima Bargal \\ M. I. T. College of Engineering, Aurangabad \\ Dr. BAM University, Aurangabad, Maharashtra, India.
}

\begin{abstract}
Design is important factor of any product as it reflects the intellectual and technical capabilities of a society and it in turns satisfies the particular customer or its user. Today all countries are known for their products and new technologies and inventions. Designs involve not only the product designs but even the structures that add value to the developing state of the state, nation or country. To make a product successful, it is necessary that it should be developed under technical expertise and it takes insight into the user experience, understanding of business objectives, and informed intuition to guide the way. This paper gives a review on the various challenges and failure that the designer faces in the whole product cycle i.e. from the thinking of a design to its final product and some overcome ideas that can help the user to identify its product. It's very important to convey the actual design which is thought according to the need of the user whose specifications can be fixed according to the survey done for that particular product.
\end{abstract}

Keywords: Industrial Product Design, Design Challenges, Engineering Design, Design Failure.

\section{Introduction}

Designing a new product can create its own new markets as well as limits the use of the existing product. The innovativeness among a new product and its extra additional features attracts the new user. Developing a new product includes the need and the unsatisfied user. The design process involves important considerations in product development and ensures that they are implemented. It is necessary to launch a new product in time or within the season. Industrial designers are working on a creative way of solving problems and the challenges that are faced by the product in its all stages of development. The idea behind utilizing the design process in a new way to add new innovativeness to a product to widen the area of market as well it is in practice in various fields. In this complete process many flaws are creates depending upon various factor such as materials, design, aesthetics, lack of innovation, etc. and these flaws needs special attention as they may kill the market of the product or even create lack of users.

\section{History}

In ancient times the designing was considered in terms of structures and their examples are seen today also. That was the best engineering in that particular era as compared to today's life. In our ancient times despite of less availability many astonishing sculptures were made. In that era, the number of products created was less but very useful in day to day chores. Need is an important factor of the product design. In ancient ages the products were too heavy but in now a day we can get very less weighing products with the latest technologies.

\section{New Trends}

Design is a sign of the times. It is in a constant change, influenced by trends with often a much wider base than the world of products. They can reflect social developments and feelings around liberation, sustainability or economics. There is a relation with fashion on the one hand and with technology on the other. Now the environment friendly designs are mostly created and used, it is also known as design for environment. Aesthetics attracts the user towards the product and make it look different and better. To succeed a product or system must provide satisfactory interaction with its user/customer on both a functional and a cultural level. The better design developed in detail and based on applied research during the design and development process plays a significant role in the competitiveness of a company.

\section{Design Process}

Product quality refers to the performance, overall design and interface design of the product/system, the manufacturing process and the product life cycle. This demonstrates the increasing importance of the role of design both for economic competitiveness and for improvement of the quality of life and work. The designer must know the parameters before starting the actual designing process such as Specifications for the Design, Understanding Customer Requirements, Marketing Requirements Specification, Design Specifications and Software Requirements. These can be known and fixed by individual survey or the need of the product. Once the objectives or the specifications are fixed then a strategy should be developed to achieve those objectives. 
While designing any product the systematic process should be carried out to avoid the errors or any accident. The designing steps involve design engineering, component engineering, reliability of components, spares requirement, preferred component list, component specifications, production engineering, test engineering, material procurement, quality assurance, and quality plan for product design, quality plan ensuring performance and reliability, and product-specific quality plan.

\section{Design Management}

Before starting the design the flow of operations must be decided that will define the flow of process and will reduce the time taken to create the product. The time period that will be needed for the total design and implementation should be fixed and accordingly maintained. The success of the product depends upon its planning and management which may be managed by a leader assigned to this work. At any condition it should be made necessary to practice the project management principles wherever possible in managing the product design.

\section{Challenge}

The society itself has become more arguable by the converging trends which are responsible for the increasing significance of product and its liability. There are many incidents that have been occurred of injury or death directly due to the poor product design or manufacture of domestic goods. The challenge for product designer is to understand the need to determine where the fault is, and it occurs when any property is damaged or any personal injury or loss of life occurs. Manufacturers operate rigorous quality check as well as quality control procedures at every stage of manufacturing. It is, therefore, not very usual for the faulty products to enter market. However, sometimes some of the faulty goods manage to slip through the mist rigorous of quality checks and enter in the domestic market and even in our homes. This may cause accidents when they are first use of when overloaded

\section{Evaluation of Designs}

The Evaluation of Design is the most important parameter of a product which will then ensure its reliability and its quality. The conceptual phase of the designing process is the most innovative phase as most of the decisions are made in that particular phase. The design engineer which corrects the flaws in designs will have to collect relevant information through careful investigation and a reverse engineering process. This is beneficial to avoid the creation of flaws at initial stage of the product. The reconstructing of failure will uncover the defect which can be present in product design, incorrect installation or even the maintenance. However, product failure can also occur due to its careless handling of an individual rather than the specific defect in its design. After assembly of the components, all products should be tested for proper functioning according to the functional test specifications drafted and agreed to by the engineering and testing departments. Functional test specifications can be changed to reduce test time after analyzing failure statistics.

Assembly instructions provide the information required to assemble the product. Assembly instructions are generated during the design phase and prepared by draftspersons. Every product must have its user manual or technical manual comprising of all the instructions on its installation, use as well as the maintenance. This will help the user to avoid the failures as well as the injuries when using the product or when overloading it. The understand level of the manuals should be kept simple as well as should be in multiple languages so as any time of user can easily understand it. The technical manuals provide the technical specifications of the product in depth depending upon the complexity of the product.

\section{Conclusion}

The quality outcome of a project is said to be achieved if the team of project has ensured to client requirements about the product delivery within the constraints identified. The user satisfaction is the more standard requirement for any product and system design. Commonly the products are designed according to the personal experience of the designers. This is not always accepted because of the concepts and expectations of the user may be different from the system. Therefore, it is very necessary that designer must understand that they need to take into consideration many different factors and study, users' needs, expectations, concepts, behavioral patterns, culture and the contextual environment in which the products are used in order to assure user's acceptance. As the products are only created or made for the users.

\section{Summary}

The major challenges in a product are created when the actual requirement and the availability differ from each other. The user also is sometimes responsible for any damage created because of the poor handling or incomplete information provided which that particular product. The concept of designing a product plays the important role in the formation of the actual product. There are many criteria in which the quality of the product 
is dependent and which defines the market of the product. The failure of a product is seen when the quality check is not proper or there is any defects in the design or the raw material used for the product. The designing of any product must be done in the systematic way with proper survey of the product according to the specification given by the user. Proper evaluation must be done in all steps of the designing process and accordingly the modifications must be done on the product. The materials play a vital role as it decides that the product will stay in the market or not. The specifications must be fixed before starting the actual process and according to that the steps must be decided for example which machinery should be used first and which operation must be done later.

\section{References}

[1] Deniz DENIZ, "Sustainability and Environmental Issues in Industrial Product Design" Izmir Institute of Technology, Turkey September, 2002.

[2] "Design as a Strategy for a Developing Economy", IDC, IIT Bombay 1989 (updated 2009)

[3] Kah-Hin Chai, Member, IEEE, and Yan Xin, Student Member, IEEE "The Application of New Product Development Tools in Industry: The Case of Singapore" IEEE Transactions On Engineering Management, Vol. 53, No. 4, November 2006543

[4] V Popovic "Product Evaluation Methods and Their Applications" School of Architecture, Interior and Industrial Design, Queensland University of Technology GPO Box 2434, Brisbane 4001, Australia

[5] "Design Product Evaluation Criteria Handbook" Office of Project Development Procedures 3/15/2013 